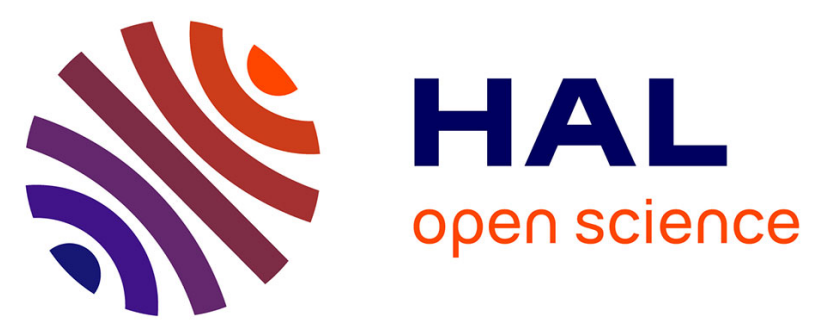

\title{
Fractionation of Suwannee River fulvic acid and Aldrich humic acid on $\alpha-\mathrm{Al} \_2 \mathrm{O} \_3$ : spectroscopic evidence
}

Francis Claret, Thorsten Schäfer, Julien Brevet, Pascal E. Reiller

\section{To cite this version:}

Francis Claret, Thorsten Schäfer, Julien Brevet, Pascal E. Reiller. Fractionation of Suwannee River fulvic acid and Aldrich humic acid on $\alpha-\mathrm{Al} \_2 \mathrm{O} \_3$ : spectroscopic evidence. Environmental Science and Technology, 2008, 42 (23), pp.8809-8815. 10.1021/es801257g . cea-00344262

\section{HAL Id: cea-00344262 \\ https://hal-cea.archives-ouvertes.fr/cea-00344262}

Submitted on 13 Sep 2019

HAL is a multi-disciplinary open access archive for the deposit and dissemination of scientific research documents, whether they are published or not. The documents may come from teaching and research institutions in France or abroad, or from public or private research centers.
L'archive ouverte pluridisciplinaire HAL, est destinée au dépôt et à la diffusion de documents scientifiques de niveau recherche, publiés ou non, émanant des établissements d'enseignement et de recherche français ou étrangers, des laboratoires publics ou privés.

\section{(1)(1) $\$(0)$}

Distributed under a Creative Commons Attribution - NonCommercial - ShareAlikel 4.0 


\section{Fractionation of Suwannee River fulvic acid and Aldrich humic acid on $\alpha-\mathrm{Al}_{2} \mathrm{O}_{3}$ : spectroscopic evidence}

FRANCIS CLARET, ${ }^{1, \dagger}$ THORSTEN SCHÄFER, ${ }^{2}$ JULIEN BREVET, ${ }^{3}$ AND PASCAL E. REILLER ${ }^{1, *}$

${ }^{1}$ Commissariat à l'Energie Atomique (CEA), CE Saclay, DEN/DANS/DPC/SECR/Laboratoire de Spéciation des Radionucléides et des Molécules, Bâtiment 391-P.C. 33, F-91191 Gif-sur-Yvette CEDEX, France

${ }^{2}$ Institut für Nukleare Entsorgung (INE), Forschungszentrum Karlsruhe, D-76021 Karlsruhe, Germany,

${ }^{3}$ Université d'Evry Val d'Essonne, Laboratoire Analyse et Environnement pour la Biologie et l'Environnement, CNRS UMR 8587, Bâtiment Maupertuis, Boulevard François Mitterrand, 91025 Evry CEDEX, France.

* Corresponding author e-mail: pascal.reiller@cea.fr

${ }^{\dagger}$ Present address BRGM, Environment and Process Division, 3 avenue Claude Guillemin, F-45060 Orleans CEDEX 2, France.

Environmental Science \& Technology (42 (23), 8809-8815

http://doi.org/10.1021/es801257g

\section{ABSTRACT}

Sorptive fractionation of Suwannee River Fulvic Acid (SRFA) and Purified Aldrich Humic Acid (PAHA) on $\alpha-\mathrm{Al}_{2} \mathrm{O}_{3}$ at $\mathrm{pH} 6$ was probed in the supernatant using different spectroscopic techniques. Comparison of dissolved organic carbon (DOC) analysis with UV/Vis spectrophotometric measurements at $254 \mathrm{~nm}$, including Specific UV absorbance (SUVA) calculation, revealed a decrease in chromophoric compounds for the non-sorbed extracts after a $24 \mathrm{~h}$ contact time. This fractionation, only observable below a certain ratio between initial number of sites of humic substances and of $\alpha-\mathrm{Al}_{2} \mathrm{O}_{3}$, seems to indicate a higher fractionation for PAHA. C(1s) near-edge X-ray absorption fine structure spectroscopy (NEXAFS) 
confirmed this trend and points to a decrease in phenolic moieties in the supernatant and to an eventual increase in phenolic moieties on the surface. Time-resolved luminescence spectroscopy (TRLS) of Eu(III) as luminescent probe showed a decrease in the ratio between the ${ }^{5} \mathrm{D}_{0} \rightarrow{ }^{7} \mathrm{~F}_{2}$ and ${ }^{5} \mathrm{D}_{0} \rightarrow{ }^{7} \mathrm{~F}_{1}$ transitions for the fractionated organic matter $(\mathrm{OM})$ that is thought to be associated to a lower energy transfer from the $\mathrm{OM}$ to $\mathrm{Eu}(\mathrm{III})$ due to the loss of polar aromatics. These modifications in the supernatant are a hint for the modification of sorbed humic extracts on the surface.

\section{Introduction}

Sorption to mineral surfaces and complexation by natural organic matter (NOM) are important processes influencing the cycling of toxic metals in the environment $(1,2)$. Metal sorption onto oxides and clays and metal binding to NOM, e.g., humic substances (HS) composed mainly of humic and fulvic acids (HA and FA), have been extensively studied. NOM influences metal migration (3), organic contaminant transport (4), and colloids stabilities $(5,6)$.

However, the specific interactions between metal cations and NOM, both in interactions with a mineral surface, are still matters of debate. The use of linear combinations of binary systems to describe ternary systems was sometimes successful (2, 7-9), but also showed significant deviations under varying HA, FA, and metal concentrations (2, 10-14), or need a semi-empirical refinement of the models (15). More recently, Weng et al. proposed the ADAPT model to account for the differences in electrostatic and chemical binding of FA and HA (16). Explanations of these discrepancies can be modifications of NOM conformation and/or composition during sorption, which can be viewed as a modification of the system 'free energy' $(2,16-18)$.

A preferential adsorption of high molecular weight fractions on oxides or kaolinite occurs in the case of aquatic NOM (19-21), whereas the adsorption of low molecular weight fractions was proposed for Aldrich HA on hematite $(22,23)$. NOM fractionation on mineral surfaces seems to depend both on the NOM origin and on the mineral. The binding of HS to mineral surface is a combination of (i) ligand exchange reaction, via carboxylic and phenolic functions, (ii) electrostatic interaction between positively charged minerals and negatively charged humic samples, (iii) possible cation bridging, and (iv) hydrophobic interactions between more or less hydrophobic moieties. It has been shown that changes in electrostatic description of HS sorbed on minerals have to be accounted for the description of their sorption (16), and that sorption on minerals (24) and change in ionic strength (25) do influence the hydrophobicity of humic sample.

Various techniques have been used to identify NOM fractionation such as chromatographic techniques based on size separation. These techniques are somehow biased by additional fractionation where UVVisible detection alone is not totally appropriate (26-28). Despite all these efforts, the identification at the molecular scale is still difficult $(29,30)$. There is a need of molecular level understanding of the sorptive fractionation processes.

HS have being used as a surrogate to estimate NOM properties. It was proposed that HS aggregation results from self-assembled molecules (31-35). The dimension of the smallest observable object is about some nanometres composing larger aggregates of some hundreds of nanometres (34). Fulvic acids only form aggregates at very high concentration (35). 
In this work, we combine results of four different techniques to obtain complementary views on the HS sorptive fractionation on $\alpha-\mathrm{Al}_{2} \mathrm{O}_{3}$ carrying aluminol sites: $\mathrm{UV}$-visible absorption (UV-Vis), total organic carbon analysis (TOC), C(1s) near edge X-ray fine structure spectroscopy (NEXAFS) and time-resolved luminescence spectroscopy (TRLS). UV-visible absorption spectra of HS are supposed to give little structural information about the functionality due to the lack of detailed and characteristic bands (36). Its use for determining HS concentration remaining in solution after sorption is unreliable (20). However, a decomposition of UV-Vis spectra to monitor the properties of NOM has been proposed (37). Considering that HS contains 'building block molecules' that differ by their substituents $(31,32)$, one can see HS, in a first approximation, as a distribution of chromophores (38). TOC analysis is the most appropriate to determine accurately the concentration of humic substances (20). Specific UV-Vis Absorbance $\left(\mathrm{SUVA}=\mathrm{A}_{254} \mathrm{~nm} / \mathrm{TOC}\right)$, is a useful approach for probing aromaticity of humic samples (39). Synchrotronbased C(1s) NEXAFS have being more recently applied to NOM study and provided semi-quantitative data on the carbon types or modification in NOM samples (40-43). TRLS have being used to study interactions of lanthanides (Ln) and actinides (An) with different organic media and to probe their chemical environment in HS (44-47). Both the spectra and luminescence bi-exponential decays of Ln-HS complexes are remarkable and permit to distinguish humic complexation from a more classical organic complexation (48, 49). Hence, using europium (III) as a luminescence probe allows obtaining a complementary view of fractionation changes in the metal binding environment.

\section{Materials and Methods}

\subsection{Sorption Experiments.}

Millipore deionized water (Alpha-Q, $18.2 \mathrm{M} \Omega \mathrm{cm}$ ) was used. SRFA is used as received from the International Humic Substance Society; its total site concentration $\mathrm{QSRFA}_{\mathrm{S}}=7.4 \mathrm{mmol} / \mathrm{g}$ is taken from ref 50. Purified Aldrich Humic Acid (PAHA) was treated following the procedure describing in ref 51, with $\mathrm{Q}_{\mathrm{PAHA}}=5.34 \mathrm{mmol} / \mathrm{g}(50)$. QHS were obtained in the framework of the NICA-Donnan model, which was applied afterward to determine the actual functionality under our conditions. Alpha alumina (Interchim, Montluçon, France) has a total site capacity for exchange of anions $\mathrm{Q}_{\alpha-\mathrm{Al}_{2} \mathrm{O}_{3}}=24 \mu \mathrm{mol} / \mathrm{g}$, and the surface properties used hereafter to determine the functionality under our conditions are in ref 52. Carbonates were removed from $\alpha-\mathrm{Al}_{2} \mathrm{O}_{3}$ surface as described in (52); the isoelectric point $\mathrm{pH}_{\mathrm{IEP}} 9.5$ was determined by zeta potential measurement (data not shown). Europium (III) stock solution was obtained from the dissolution of $\mathrm{Eu}_{2} \mathrm{O}_{3}$ (Johnson Matthey, 99.99\%) in $\mathrm{HClO}_{4}$ 70\% (Merck, GR for analysis).

Sorption studies were performed at $\mathrm{pH} 6.1 \pm 0.1$ because of the high variation of sorption results awaited for this kind of mineral phase vs. HS concentration (16). All the suspensions, solutions, and dilutions were done by weighing. The ionic strength $I$ was fixed with $\mathrm{NaClO}_{4}$ to $0.1 \mathrm{~mol} / \mathrm{kg}_{\mathrm{H}_{2} \mathrm{O}}(\mathrm{m})$ and $\mathrm{pH}$ was adjusted using freshly prepared $\mathrm{NaOH}$ and $\mathrm{HClO}_{4}$. The $\mathrm{pH}$ measurements were done using a combined-glass electrode (Radiometer Analytical XC111) calibrated for its linear response with a $0.01 \mathrm{~m} \mathrm{HClO}_{4}$ solution, an equimolal $0.02 m \mathrm{NaH}_{2} \mathrm{PO}_{4} / \mathrm{Na}_{2} \mathrm{HPO}_{4}$ solution, and an equimolal $0.02 m \mathrm{Na}_{2} \mathrm{CO}_{3} / \mathrm{NaHCO}_{3}$ solution, all containing $\mathrm{NaClO}_{4}$ to keep $\left[\mathrm{Na}^{+}\right]$constant at $0.1 m(\mathrm{pH}=2,6.785$, and 9.9 respectively). The electrode

filling solution was modified with $\mathrm{NaClO}_{4} 0.1 \mathrm{~m}, \mathrm{NaCl} 10^{-2} \mathrm{~m}$ to prevent $\mathrm{KClO}_{4}$ precipitation in the frit of the electrode. 
Batch sorption experiments were conducted at room temperature $\left(22 \pm 1{ }^{\circ} \mathrm{C}\right)$. Weighed aliquots of $\alpha-\mathrm{Al}_{2} \mathrm{O}_{3}, \mathrm{NaClO}_{4}$, and humic solution, were suspended in milli-Q water. The detailed results are presented in Table S1 in supplemental information (SI). The suspensions were shaken for 24 hours and $\mathrm{pH}$ was measured afterwards until a constant value was reached (usually 2 to 4 hours). This contact time is sufficient to obtain a quasi-equilibrium. Some works seem to indicate that exchange between the HS, or NOM sub-fractions, is still occurring up to 900 days $(22,53)$.

The solid phase was separated via a pre-centrifugation step performed in $30 \mathrm{~mL}$ Nalgene $3137-0030$ centrifuge vials $(50,000 \mathrm{~g}$ for 1 hour); the supernatant was then ultra-centrifuged in order to settle remaining colloidal particles in $10 \mathrm{~mL}$ Beckman 355603 vials (246,960 g for 1 hour). Modifications of the HS composition induced by this centrifugation steps can be ruled out as for the PAHA $/ \alpha-\mathrm{Fe}_{2} \mathrm{O}_{3}$ system (30). No filtration step was done before absorbance measurement and particular caution was taken during the sampling to avoid resuspended colloidal particles. Supernatant spectra were consecutively measured using a Shimadzu UV-3150 spectrophotometer and TOC in solution was determined with a Shimadzu 5000 TOC analyzer after acidification and purging with argon. The uncertainties of the determinations were obtained from the regression analyses of the calibrations curves built from weighed aliquots of HS.

\section{$2.2 C(1 s)$ NEXAFS}

Carbon K-edge NEXAFS spectra were measured at the Scanning Transmission X-ray Microscopy (STXM) beamline X1A1 (NSLS), operated by the State University of New York at Stony Brook, USA. The principle of the methods is described elsewhere (54). STXM sample preparation was performed by drying $1 \mu \mathrm{L}$ of $\mathrm{HS}$ solution for supernatant, and after deposition of the HS-covered $\alpha-\mathrm{Al}_{2} \mathrm{O}_{3}$, on a $\mathrm{Si}_{3} \mathrm{~N}_{4}$ window (100 nm thick). For the supernatant, depending on the organic concentration the spectra was either (i) extracted from images taken at different energies across the absorption edge (stacks method) after aligning them using cross-correlation (55), or (ii) measured by the point spectra procedure (43). The two methods gave comparable results on the same samples. The spectra of the HS-covered $\alpha-\mathrm{Al}_{2} \mathrm{O}_{3}$ samples had a very low signal to noise ratio. Energy calibration of the spherical grating monochromator was achieved by using the photon energy of the $290.74 \mathrm{eV} \mathrm{CO}_{2}$ gas adsorption band (56). For comparison, all NEXAFS spectra were baseline corrected and normalized to 1 at $295 \mathrm{eV}$.

\subsection{Analysis of UV/Vis spectra.}

UV/Vis spectra of HS show a classical strong steady increase with decreasing wavelength. In HS, the majority of the chromophores that absorbs in UV are aromatic groups with various degrees of substitution $(37,57)$. In analogy to benzene, a simplified decomposition approach to allow a better understanding of the chromophoric group functionalities was proposed (37). The 200-400 nm region represents three simulated bands; a very intense local excitation band (LE) around $180 \mathrm{~nm}$, a benzenoid band (Bz) around $203 \mathrm{~nm}$ due to vibrational perturbations in the $\pi$-electron system, and a low intensity electron transfer band (ET) around $253 \mathrm{~nm}$ due to strong quantum-mechanical prohibition but strongly affected by the presence of polar groups. The spectra are then fitted with the sum of the three Gaussians using a nonlinear regression fitting procedure. 


\subsection{TRLS}

Europium(III) was used to probe the luminescence properties in the supernatant. Eu(III) shows a luminescence spectrum corresponding to the ${ }^{5} \mathrm{D}_{0} \rightarrow{ }^{7} \mathrm{~F}_{\mathrm{j}}$ transition manifold (58). The luminescence properties of $\mathrm{Eu}(\mathrm{III})$ in the supernatant were compared to those in the original humic samples.

The excitation laser beam was generated by a $355 \mathrm{~nm}$ tripled output of a Continuum Nd-YAG laser, coupled to an optical parametric oscillator system (Panther II, Continuum, USA). The wavelength was tuned to $394.6 \mathrm{~nm}$, providing about $1.6 \mathrm{~mJ}$ of energy in a $5 \mathrm{~ns}$ pulse with a repetition rate of $10 \mathrm{~Hz}$. The luminescence signal is collected at $90^{\circ}$ and focused into an Andor spectrometer (550-650 nm, resolution $0.2 \mathrm{~nm}$ ). The signal is collected during a gate width of $300 \mu \mathrm{s}$, at a gate delay of $10 \mu \mathrm{s}$ after excitation by the laser flash. To increase the signal to noise ratio, every spectrum was accumulated 1,000 times. Emission spectra were recorded between using a CCD camera cooled at $-15^{\circ} \mathrm{C}$. Only ${ }^{5} \mathrm{D}_{0} \rightarrow{ }^{7} \mathrm{~F}_{0}$ (around $580 \mathrm{~nm}$ ), ${ }^{5} \mathrm{D}_{0} \rightarrow{ }^{7} \mathrm{~F}_{1}$ (around $593 \mathrm{~nm}$ ), and ${ }^{5} \mathrm{D}_{0} \rightarrow{ }^{7} \mathrm{~F}_{2}$ (around $615 \mathrm{~nm}$ ) bands can be observed. Before TRLS measurement the $\mathrm{pH}$ was adjusted to 4 to limit the signal from $\mathrm{EuOH}^{2+}$ and $\mathrm{EuCO}_{3}{ }^{+}$at $\mathrm{pH} 6$.

\section{Results and Discussion}

\subsection{UV/VIS, TOC, and SUVA analyses.}

In Figure 1a, the distribution coefficients:

$\mathrm{R}_{\mathrm{d}}(\mathrm{mL} / \mathrm{g})=\frac{[\mathrm{HS}]_{\text {sorbed }}(\mathrm{mol} / \mathrm{g})}{[\mathrm{HS}]_{\text {solution }} \mathrm{mol} / \mathrm{mL}}=\frac{[\mathrm{HS}]_{\text {sorbed }}}{[\mathrm{HS}]_{\text {initial }}-[\mathrm{HS}]_{\text {sorbed }}} \times \frac{\mathrm{V}(\mathrm{mL})}{\mathrm{m}_{\alpha-\mathrm{Al}_{2} \mathrm{O}_{3}}(\mathrm{~g})}$

of sorbed HS onto $\alpha-\mathrm{Al}_{2} \mathrm{O}_{3}$ are plotted vs. the ratio $\mathrm{R}_{\mathrm{HS}}$ of initial available sites in $\mathrm{HS}$ and $\alpha-\mathrm{Al}_{2} \mathrm{O}_{3}$ defined as:

$\mathrm{R}_{\mathrm{HS}}\left(\mathrm{mol} \cdot \mathrm{g}_{\mathrm{HS}}^{-1} / \mathrm{mol} \cdot \mathrm{g}_{\alpha-\mathrm{Al}_{2} \mathrm{O}_{3}}^{-1}\right)=\frac{\mathrm{Q}_{\mathrm{HS}}\left(\mathrm{mol} \cdot \mathrm{g}_{\mathrm{HS}}^{-1}\right)}{\mathrm{Q}_{\alpha-\mathrm{Al}_{2} \mathrm{O}_{3}}\left(\mathrm{~mol} \cdot \mathrm{g}_{\alpha-\mathrm{Al}_{2} \mathrm{O}_{3}}^{-1}\right)} \times \frac{\mathrm{C}_{\mathrm{HS}}\left(\mathrm{mg}_{\mathrm{HS}} \cdot \mathrm{kg}_{\mathrm{H} 2 \mathrm{O}}^{-1}\right)}{\mathrm{C}_{\alpha-\mathrm{Al}_{2} \mathrm{O}_{3}}\left(\mathrm{mg}_{\alpha-\mathrm{Al}_{2} \mathrm{O}_{3}} \cdot \mathrm{kg}_{\mathrm{H} 2 \mathrm{O}}^{-1}\right)}$

The $R_{d}$ notation reflects that under our conditions the final hypothetical equilibrium conditions is not reached and that reversibility is not ascertained (59). The concentrations of HS are either determined from the calibration in UV-Vis, which is known to be biased for sorbed samples (26), and in TOC. The adsorption isotherms are reported in SI (Figure S1a). The sorption is constant between 1 and 48 hours (data not shown) and there is no evolution of the SUVA vs. time for $\mathrm{R}_{\mathrm{PAHA}}=10.4$ (Figure S1b). The latter figure confirmed that fast HS sorption was occurring on aluminum oxides as it had already been noticed for iron oxides (20). 

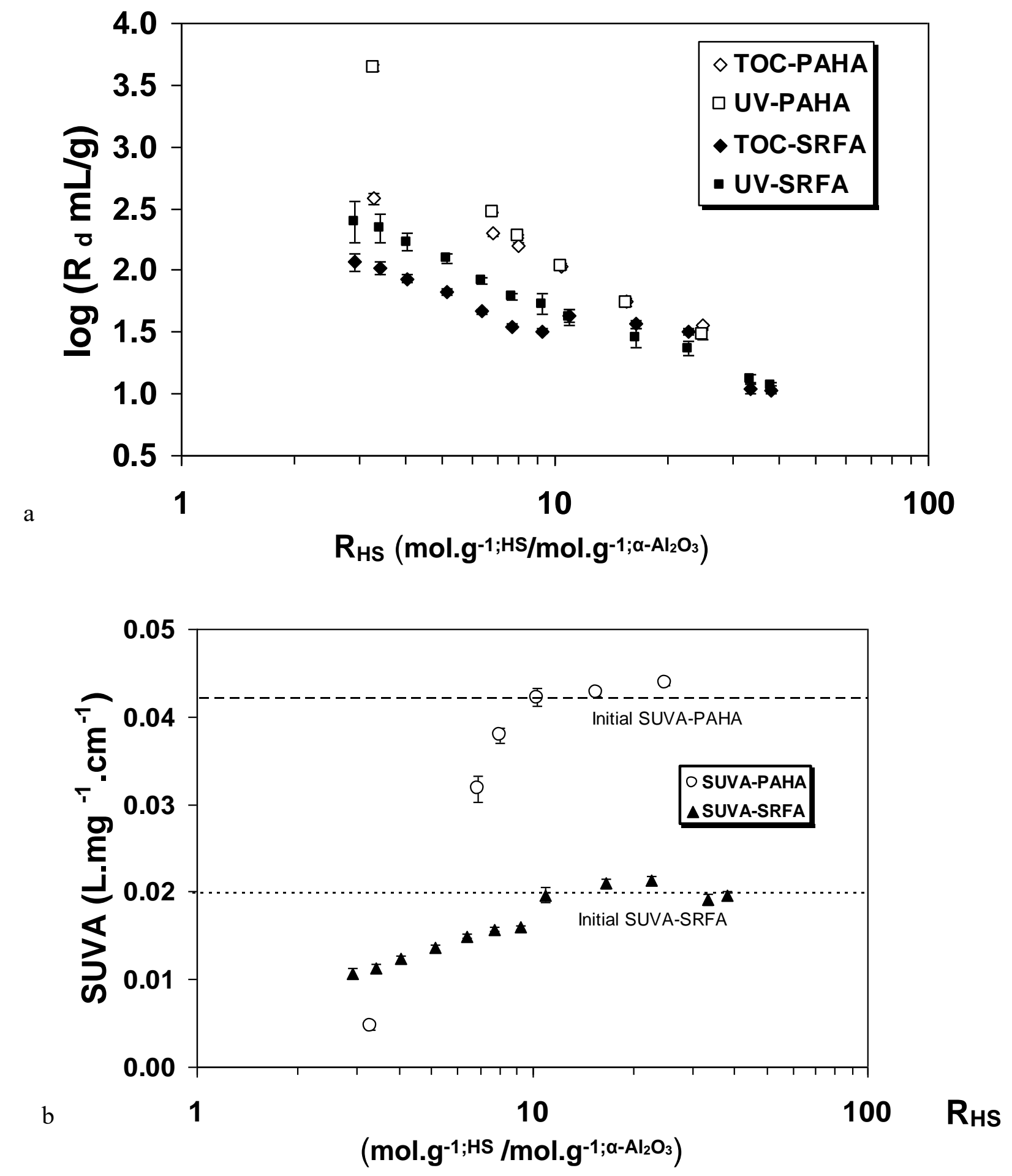

Figure 1. Evolution of $\mathrm{R}_{\mathrm{d}}(\mathrm{mL} / \mathrm{g}$ ) for SRFA (closed symbols) and PAHA (open symbols) adsorbed on $\alpha-\mathrm{Al}_{2} \mathrm{O}_{3}$ determined in UV-Vis (square) and TOC (diamonds) as a function of $\mathrm{R}_{\mathrm{HS}}$ (a), and SUVA from the same experiments for PAHA (O) and SRFA ( $\mathbf{\Delta})(\mathrm{b}), \mathrm{pH}$ 6, I=0.1 $\mathrm{m}$.

$\mathrm{R}_{H S}$ can be viewed as a dimensionless number representing the amount of humic sites present on the mineral surface that bears its own functionality. It could permit to directly compare different sets of experiments done under different concentration conditions, different functionalities (humic and fulvic, hydroxides and oxides) or different surface properties (silica, iron or aluminum oxides). It could also be 
used to evidence an overcompensation of humic functionality compared to the available surface sites as in ref 60 . Application to clays could be more difficult.

In Figure 1a, $R_{d}(P A H A)>R_{d}(S R F A)$ as in ref 61 . When $R_{H S}<10, R_{d}$ obtained by UV/Vis are higher than determined by TOC. This can also be seen on the normalized absorption spectra (Figure S2 and S3 of SI). This was observed for NOM sorption on oxides $(20,37)$. The SUVA in Figure 1b monitors the same trend. Initial SUVA for PAHA is more important than SRFA due to a more important specific absorbance. This representation results in a change in slope around $\mathrm{R}_{\mathrm{HS}} \approx 10$ corresponding to the point where UV/Vis and TOC do not correspond (Figure 1a). The greater decrease in SUVA for PAHA indicates a greater fractionation of aromatic moieties. The fractionation is thus only observable when $\mathrm{R}_{\mathrm{HS}} \leq 10$ but is occurring under all $\mathrm{R}_{\mathrm{HS}}$ conditions. This loss of polar aromatic in the supernatant must imply an enrichment of aromatic moieties at the surface.

\subsection{NEXAFS analyses and UV/Vis decompositions.}

C(1s) NEXAFS measurements are presented on Figure 2a,b for HS supernatants. Only the HS-covered $\alpha-\mathrm{Al}_{2} \mathrm{O}_{3}$ sample having $\mathrm{R}_{\mathrm{HS}} \leq 10.9$ were analyzed. These spectra revealed very low signal to noise ratio compared to the quality of data for clays (62). The most plausible reason of these low signal is a more homogeneous covering of oxides and the occurrence of more dense and 'strong spots', on the CallovoOxfordian argillite. Only data for the most concentrated sample, i.e., $\mathrm{R}_{\mathrm{SRFA}}=10.9$, could be analyzed (Figure S4 and Figure 2a).

The detailed band assignment of FA via correlation with ${ }^{1} \mathrm{H}$ and ${ }^{13} \mathrm{C}$ NMR is referred to ref 40 , knowing that uncertainties exist when transferring the band assignment to other organic systems both concerning the absolute intensity response of electron transitions and assignment of functional groups due to overlapping resonance ranges of electron transitions (63).

The spectra of the initial HS show three main peaks at 285.2, 286.6, and $288.6 \mathrm{eV}$ corresponding to the $\mathrm{C}(1 \mathrm{~s}) \rightarrow \pi^{*}$ transitions. The $285.2 \mathrm{eV}$ band corresponds to aromatic $\mathrm{C}-\mathrm{C}$ or $\mathrm{C}-\mathrm{H}$ bonds (64). The $286.6 \mathrm{eV}$ transition can be assigned to aromatic $\mathrm{C}-\mathrm{O}$ (phenols) or $\mathrm{C}-\mathrm{X}$ (halogen) bonds (64). The most intense band around $288.6 \mathrm{eV}$ is related to the oscillation strength of the $\mathrm{C}=\mathrm{O}$ bonds of carboxylic groups $(65,66)$. This latter peak is clearly asymmetric providing evidence that both the $289.5 \mathrm{eV}$ transition, assigned to the O-alkyl group of alcohols/carbohydrates, and the mixed Rydberg valence band around $287.4 \mathrm{eV}$, generally assigned to aliphatic groups, are masked (67). The very small $290.2 \mathrm{eV}$ peak can be assigned to remaining carbonates $(68)$.

A steady decrease in aromatic and phenol-type groups occurs when $\mathrm{R}_{\mathrm{HS}} \leq 6$. This effect is pronounced for $\mathrm{R}_{\mathrm{SRFA}}=2.9$. The same trend is observed for PAHA, but a strong fractionation of aromatics is still visible at $\mathrm{R}_{\mathrm{PAHA}}=6.9$, whereas at $\mathrm{R}_{\mathrm{SRFA}}=10.9$ the spectrum looks already similar to initial SRFA.

The C(1s) NEXAFS spectra confirm the SUVA results and give a direct spectroscopic proof that the observed difference between TOC and UV/Vis can be likely both attributed to a reduction of aromatic functional group (peak decrease at $285 \mathrm{eV}$ ) and chromophoric groups with polar aromatic functionalities, i.e. mostly phenolic. 


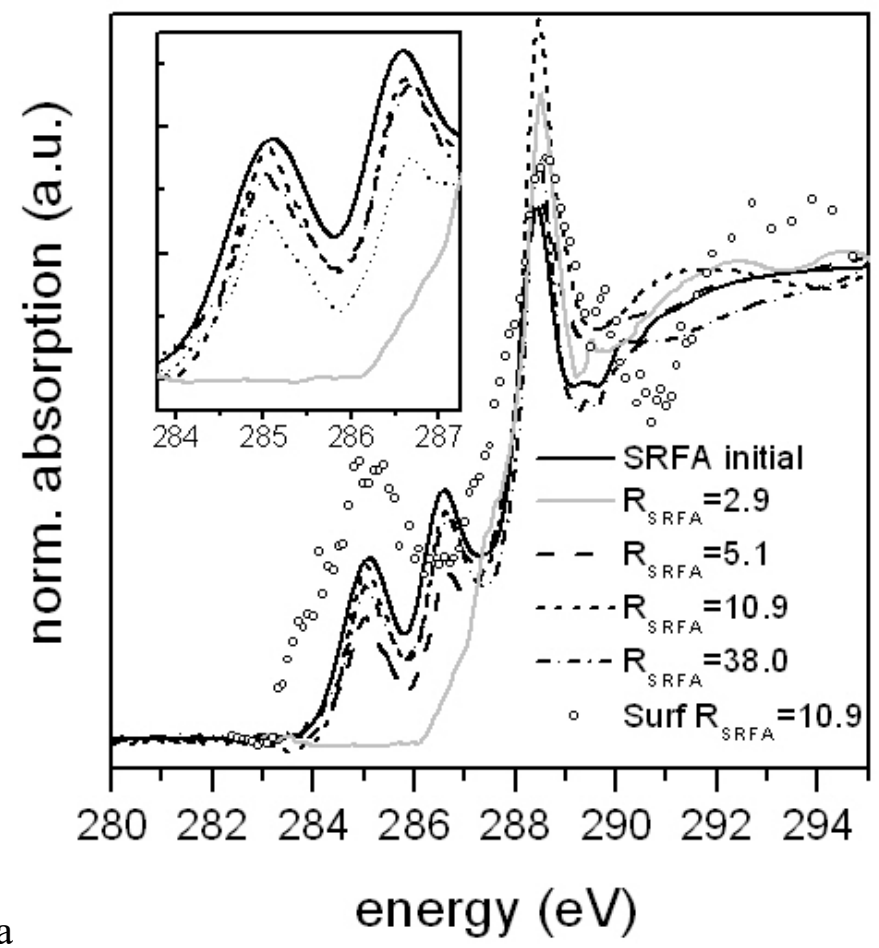

a

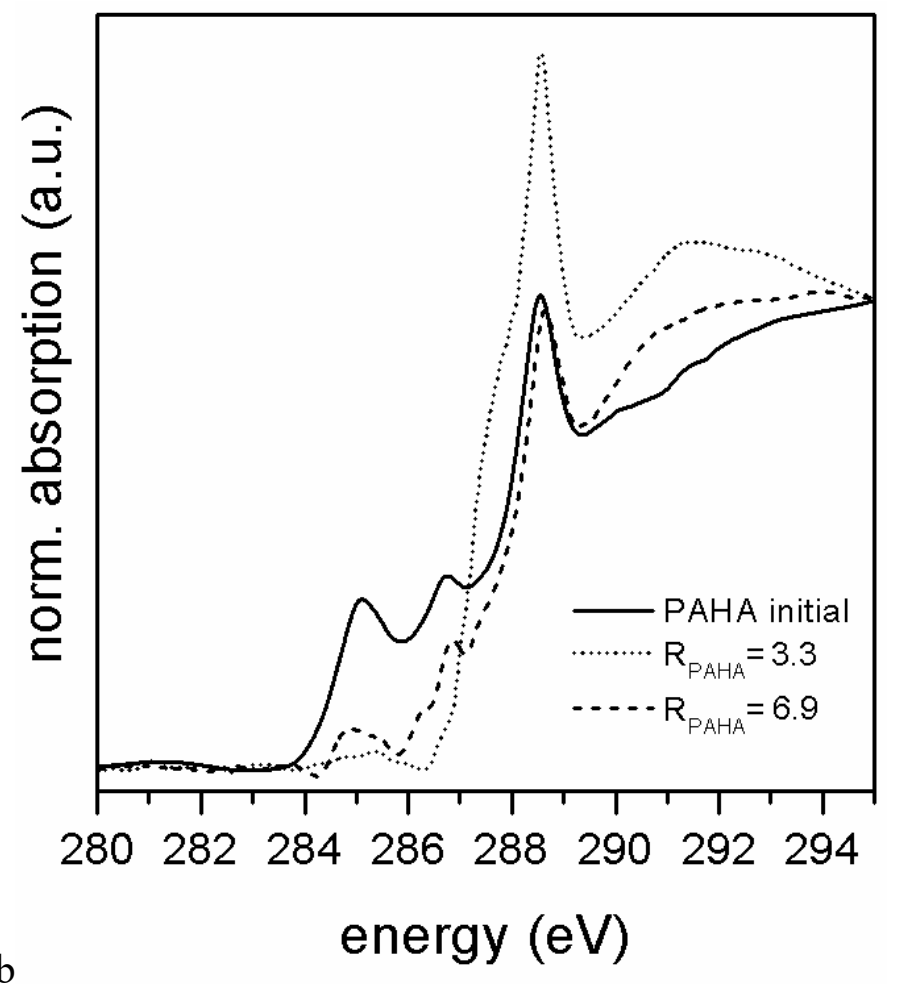

Figure 2. C(1s) NEXAFS spectra obtained before sorption (plain line), for the supernatant after adsorption on $\alpha-\mathrm{Al}_{2} \mathrm{O}_{3}$ for different ratio $\mathrm{R}_{\mathrm{HS}}$ for SRFA (grey $\mathrm{R}_{\mathrm{SRFA}}=2.9$, dashed $\mathrm{R}_{\mathrm{SRFA}}=5.1$, dotted $\mathrm{R}_{\mathrm{SRFA}}=10.9$, dash-dot $\mathrm{R}_{\mathrm{SRFA}}=38$ ), and smoothed spectrum for HS-covered $\alpha-\mathrm{Al}_{2} \mathrm{O}_{3}$ at $\mathrm{R}_{\mathrm{SRFA}}=10.9$ (original spectrum in Figure S4) (a), and supernatant PAHA (dashed RPAHA $=6.9$, dotted RPAHA $=3.3$ ) (b), $\mathrm{pH} 6.1, I=0.1 \mathrm{~m}$.

Even if the spectrum of HS-covered $\alpha-\mathrm{Al}_{2} \mathrm{O}_{3}$ sample at $\mathrm{RSRFA}=10.9$ was exhibiting a low signal to noise ratio (Figure S4), two peaks can be distinguished, around $285 \mathrm{eV}$ and $289 \mathrm{eV}$. A Savitzky-Golay smoothing (5 points, Origin 8.0) was applied to the spectrum giving the circles on Figure 2a. Other solid samples could not even be smoothed to extract reliable signal. From this smoothed spectrum, it seems that 
the contribution around $285.2 \mathrm{eV}$ (aromatic carbons) is higher than both the initial SRFA and the corresponding fractionated SRFA. The contribution around $288.6 \mathrm{eV}$ (carboxylic carbons) is slightly higher than the original sample and comparable to the fractionated sample. It could be inferred that enrichment of aromatic moieties on the mineral surface is occurring, but considering the extensive smoothing, these data should be taken with great care.

UV/Vis spectra were decomposed following ref 37 (see equation S2, Figure S2 and S3, Table S1 and $\mathrm{S} 2$ in $\mathrm{SI}$ ), giving $\mathrm{A}_{0, \mathrm{LE}}, \mathrm{A}_{0, \mathrm{Bz}}$, and $\mathrm{A}_{0, \mathrm{ET}}$ the maximum absorbance of the $\mathrm{LE}, \mathrm{Bz}$, and ET bands, respectively; $\Delta_{\mathrm{LE}}, \Delta_{\mathrm{Bz}}$, and $\Delta_{\mathrm{ET}}$ the full widths at mid height of the decomposed bands; $\mathrm{E}_{0, \mathrm{LE}}, \mathrm{E}_{0, \mathrm{Bz}}$, and $\mathrm{E}_{0, \mathrm{ET}}$ are fixed at $180 \mathrm{~nm}, 203 \mathrm{~nm}$, and $253 \mathrm{~nm}$, respectively (37). The $\mathrm{A}_{0, \mathrm{E}} / \mathrm{A}_{0, \mathrm{Bz}}$ ratios, which monitors the proportion of aromatics that contains polar groups, are plotted vs. $\mathrm{R}_{\mathrm{HS}}$ (Figure 3 ). In the region of comparable UV/Vis and TOC $\left(\mathrm{R}_{\mathrm{HS}}>10\right), \mathrm{A}_{0, \mathrm{ET}} / \mathrm{A}_{0, \mathrm{Bz}} \approx 0.6$ for SRFA and $\mathrm{A}_{0, \mathrm{ET}} / \mathrm{A}_{0, \mathrm{Bz}} \approx 1.2$ for PAHA indicating that PAHA contains more polar aromatic groups (37). For $\mathrm{R}_{\mathrm{SRFA}}<10, \mathrm{~A}_{0, \mathrm{Et}} / \mathrm{A}_{0, \mathrm{Bz}}$ is slightly but significantly decreasing to values around 0.5 . This decrease is more pronounced for PAHA and is in line with SUVA evolution. This is an indication of a stronger fractionation of PAHA as seen in SUVA and STXM. This is also due to the increasing importance of the LE band in the fit (Table S1 and S2 in SI), which decreases the relative importance of $\mathrm{A}_{0, \mathrm{Bz}}$. The decrease of $\mathrm{A}_{0, \mathrm{ET}} / \mathrm{A}_{0, \mathrm{Bz}}$ and of $\Delta_{\mathrm{ET}} / \Delta_{\mathrm{Bz}}$ (Figure S5 of the SI), and the increase of $\mathrm{A}_{0, \mathrm{LE}}$ (Table S1 in SI) indicate preferential removal of HS molecules that contain higher than average concentrations of aromatic units activated with oxygen-containing functional groups in the supernatant, i.e. phenolic, benzoic, aromatic esters and carbonyl groups (37, 57). This is in line with the loss of phenolic groups in NEXAFS, and with the PAHA/ $\alpha-\mathrm{Fe}_{2} \mathrm{O}_{3}$ system (30). Another interpretation might be a hypochromism effect (69), which would imply a reversible self-association of molecules. A combination of the two phenomena is more likely.

The correlation between NEXAFS and $\mathrm{A}_{0, \mathrm{Et}} / \mathrm{A}_{0, \mathrm{Bz}}$ presented in Figure 3 confirms that the changes in slopes are occurring for $\mathrm{R}_{\mathrm{HS}} \approx 10$; we cannot fully ascertain the trend for PAHA. The phenomena underlying UV-Vis and NEXAFS are not directly comparable but the trends are strikingly similar. Direct correlations are useless for the moment being as when $\mathrm{R}_{\mathrm{HS}} \leq 3.5$ no aromatics can be detected in STXM. 


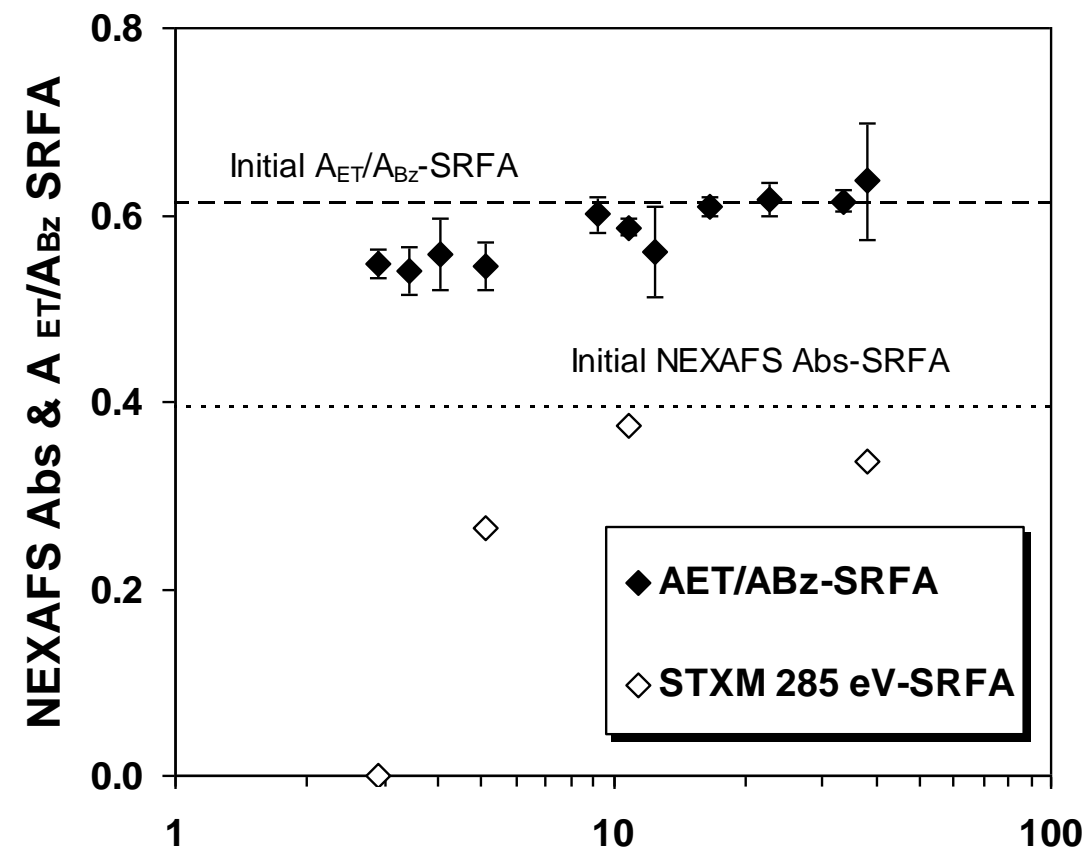

a

$$
\text { RsRFA (mol.g-1;SRFA } / \text { mol.g }^{-1 ; \alpha-\mathrm{Al}_{2} \mathrm{O}_{3}} \text { ) }
$$

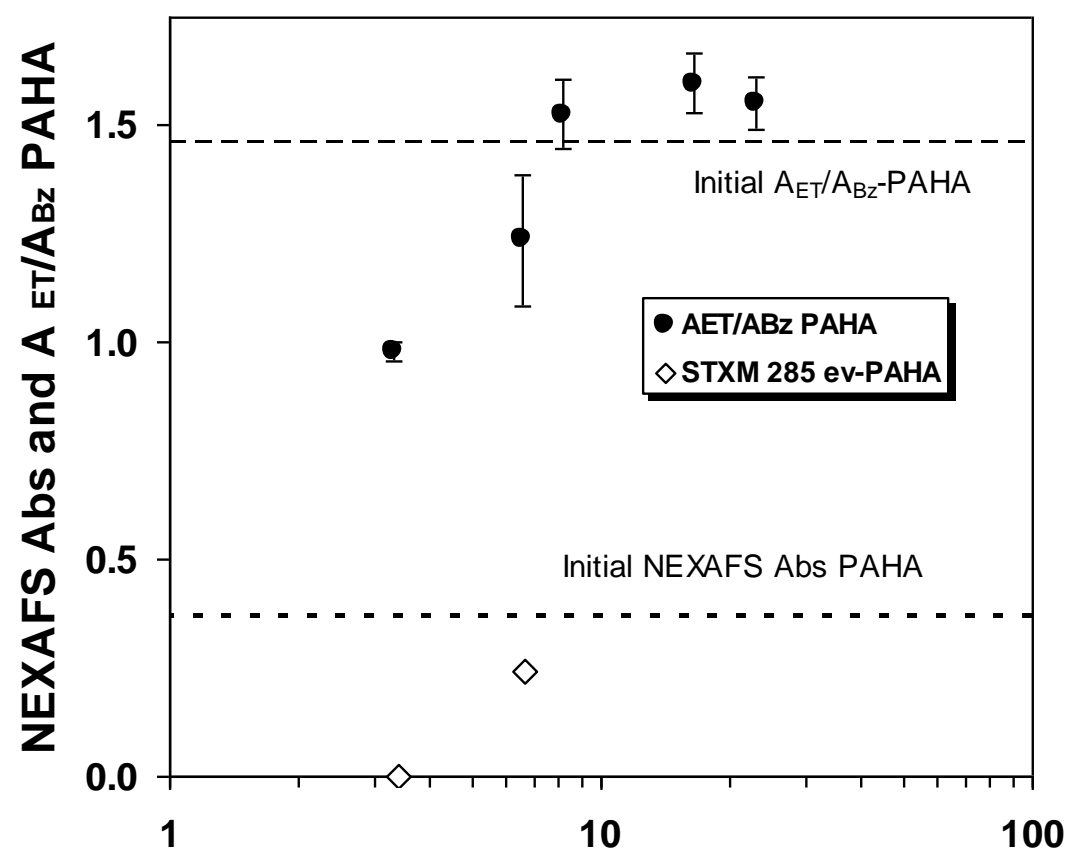

b

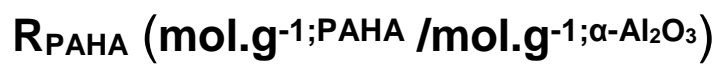

Figure 3. The $A_{0, E T} / A_{0, B z}$ and NEXAFS peak height for SRFA (a) and PAHA (b) for different ratios of available sites, $\mathrm{pH}$ 6,1, I=0.1 $\mathrm{m}$. The original data are reported in Figure S2 and S3, and in Table S1 and S2 of the SI 


\subsection{TRLS}

The ratio between ${ }^{5} \mathrm{D}_{0} \rightarrow{ }^{7} \mathrm{~F}_{2}$ and ${ }^{5} \mathrm{D}_{0} \rightarrow{ }^{7} \mathrm{~F}_{1}$ bands (under our conditions ${ }^{7} \mathrm{~F}_{2} /{ }^{7} \mathrm{~F}_{1}=\mathrm{I}_{615} \mathrm{~nm} / \mathrm{I}_{593} \mathrm{~nm}$ ) is an indication of the chemical environment of $\mathrm{Eu}(\mathrm{III})$; the ${ }^{5} \mathrm{D}_{0} \rightarrow{ }^{7} \mathrm{~F}_{2}$ transition is hypersensitive to changes in the chemical environment. In Figure $4,{ }^{7} \mathrm{~F}_{2} /{ }^{7} \mathrm{~F}_{1}$ are plotted vs. [Eu(III)]/TOC $\left(\mu \mathrm{mol} \mathrm{Eu}_{\mathrm{mg}} / \mathrm{mg}_{\mathrm{C}}\right.$ for experiments with supernatants and the original HS. For aqueous $\mathrm{Eu}^{3+},{ }^{7} \mathrm{~F}_{2} /{ }^{7} \mathrm{~F}_{1}=0.25$ (dash-dotted line) (44, 49), whereas for a complete binding of $\mathrm{Eu}(\mathrm{III})$ to $\mathrm{HS}$, i.e. $[\mathrm{Eu}] / \mathrm{TOC}=0.03,{ }^{7} \mathrm{~F}_{2} /{ }^{7} \mathrm{~F}_{1} \approx 2.5$ as in ref 45 . The increase is slightly steeper in the case of $\mathrm{PAHA}_{0}$ when compared to the available functionality $\left(\mathrm{Q}_{\mathrm{PAHA}}=\right.$ $1.75 \mathrm{mmol} / \mathrm{g}$, and $\mathrm{Q}_{\mathrm{SRFA}}=3.9 \mathrm{mmol} / \mathrm{g}$ at $\mathrm{pH} \mathrm{4}$, see figure $\mathrm{S} 6$ in $\mathrm{SI}$ ), indicating that PAHA seems to have slightly stronger complexation capacity for lanthanides-actinides (III) than SRFA, which was also shown for other samples $(70,71)$.

For the supernatant, when $\mathrm{R}_{\mathrm{HS}} \geq 10$, the ${ }^{7} \mathrm{~F}_{2} /{ }^{7} \mathrm{~F}$ evolution is close to original samples; conversely, when $\mathrm{R}_{\mathrm{HS}} \leq 10,{ }^{7} \mathrm{~F}_{2} /{ }^{7} \mathrm{~F}_{1}$ decreases for comparable [Eu]/TOC ratio. One can remark that ${ }^{7} \mathrm{~F}_{2} /{ }^{7} \mathrm{~F}_{1}$ evolutions are similar for $\mathrm{R}_{\mathrm{SRFA}}=16.5$ and $\mathrm{R}_{\mathrm{PAHA}}=15.9$, and that the increase at $\mathrm{R}_{\mathrm{SRFA}}=5.1$ is slightly lower that for $\mathrm{R}_{\text {PAHA }}=6.9$.

Energy transfer from the excited state of the complexed ligand to the ${ }^{5} \mathrm{D}_{0}$ level of Eu(III), leading to a luminescence enhancement, is generally taking place over the triplet levels in the chromophores via the 'antenna effect' (72). It could be inferred that this energy transfer is less efficient for fractionated organic matter due to the loss of polar aromatic moieties. For the supernatant at $\mathrm{R}_{\mathrm{SRFA}}=5.1,{ }^{7} \mathrm{~F}_{2} /{ }^{7} \mathrm{~F}_{1} \approx 1$ when $[\mathrm{Eu}] / \mathrm{TOC}=0.03 \mu \mathrm{mol}_{\mathrm{Eu}} \mathrm{g}_{\mathrm{C}}^{-1}$ as for complete complexation of glycolic acid (49); for $\mathrm{R}_{\mathrm{PAHA}}=3.3$, when $[\mathrm{Eu}] / \mathrm{TOC}=0.08 \mu \mathrm{mol}_{\mathrm{Eu}} \cdot \mathrm{g}_{\mathrm{C}}^{-1},{ }^{7} \mathrm{~F}_{2} /{ }^{7} \mathrm{~F}_{1} \approx 0.5$ indicating a more pronounced decrease in energy transfer, in agreement with STXM, $\mathrm{A}_{0, \mathrm{ET}} / \mathrm{A}_{0, \mathrm{Bz}}$, and SUVA.

The evolutions of ${ }^{7} \mathrm{~F}_{2} /{ }^{7} \mathrm{~F}_{1}$ vs. [Eu]/TOC on Figure 4 look like complexation isotherms. It was not possible to perform acid-base titrations of HS in the supernatant because of their low concentration. Furthermore, it was not possible to attain the plateau indicating the complete complexation, it is then impossible to calculate any interaction parameter related to a number of sites. Nonetheless, it seems that the supernatants have a lesser degree of interaction with $\mathrm{Eu}(\mathrm{III})$ than original samples as the half reaction point is shifted to higher carbon concentrations with decreasing $R_{H S}$ values. It seems then that humic and fulvic acids in the supernatant have a lesser affinity with $\mathrm{Eu}^{3+}$. It is up to now not possible to conclude on this matter as long as the functionality of non-sorbed fulvic fraction cannot be quantified. Should nonsorbed sample be different from the original samples, then sorbed samples should also have different properties than the original humic substances due to the relative enrichment of both polar aromatic groups at the surface, as postulated from STXM results, and modification of functionality (4). 


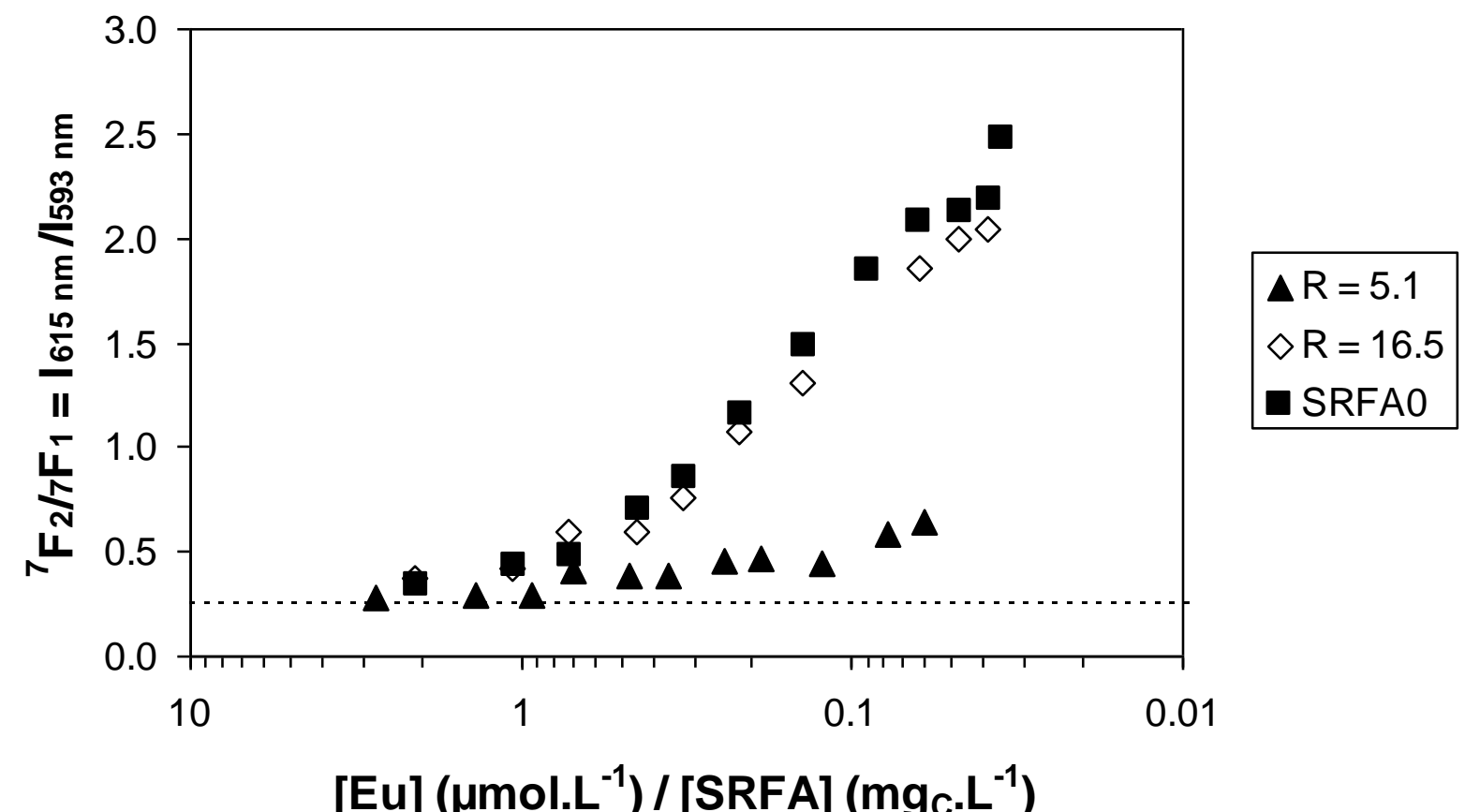

a

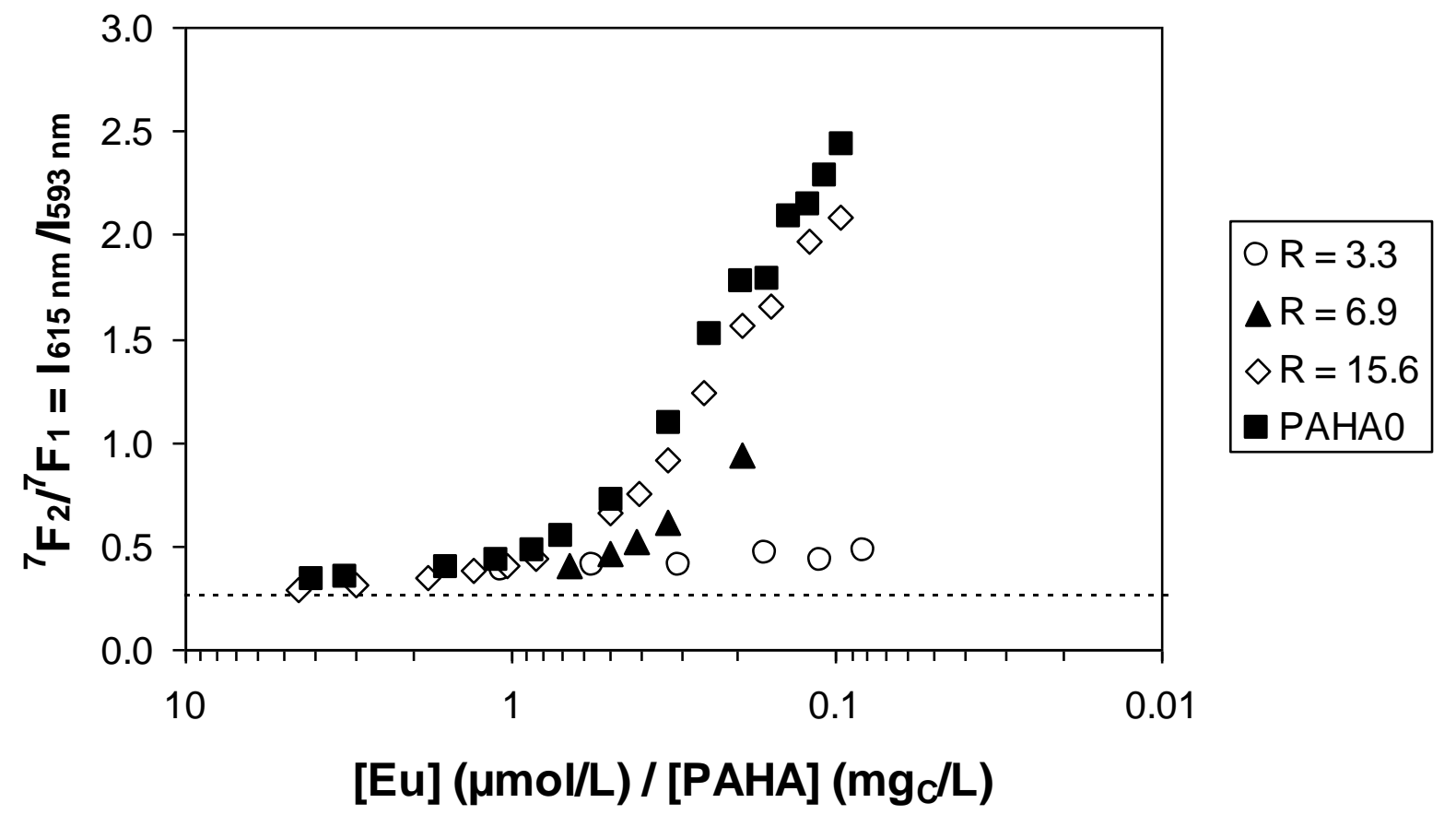

b

Figure 4. Evolution of the ${ }^{7} \mathrm{~F}_{2} /{ }^{7} \mathrm{~F}_{1}$ peak height ratio as a function of $[\mathrm{Eu}(\mathrm{III})] / \mathrm{TOC}\left(\mu \mathrm{mol}_{\mathrm{Eu}} \cdot \mathrm{L}^{-1} / \mathrm{mg}_{\mathrm{C}} \cdot \mathrm{L}^{-1}\right)$ for SRFA (a) and PAHA (b), and for different values of $\mathrm{R}_{\mathrm{HS}}, \mathrm{pH}$ 4.0, $I=0.1 \mathrm{~m}$ : dash-dotted line is the ${ }^{7} \mathrm{~F}_{2} /{ }^{7} \mathrm{~F}_{1}$ ratio of $\mathrm{Eu}^{3+}$ at $\mathrm{pH} 4$.

Acknowledgment. We acknowledge beamtime allotment by BNL/NSLS, B. Amekraz and C. Moulin from CEA for helpful discussions, anonymous reviewers for contributing in the manuscript enhancement, and Pr. Ruben Kretzschmar for his patience in editorial handling. This work was financed through the 'FUNMIG project' (EC: FUNMIG-NUWASTE-2004-3.2.1.1-1), the 'OMMI' project (MERG-CT-2005- 
012338), and the MRTRA project of the Risk Control Domain (CEA/DEN/DDIN/MRTRA) and the CHSOL project of the Basic Research Domain (CEA/DEN/DSOE/RdB) of CEA.

The supplemental information gives: the sorption isotherm expressed as free HS concentration vs. total HS concentration; the kinetic evolution of SUVA and sorption $\%$ for $\mathrm{R}_{\mathrm{PAHA}}=10.4$; the normalized UVVis absorbance spectra of initial SRFA, PAHA, and supernatants after sorption on $\alpha-\mathrm{Al}_{2} \mathrm{O}_{3}$ at $\mathrm{pH}$ 6.1 for different values of available sites ratio $\mathrm{R}_{\mathrm{HS}}$; the initial spectrum of HS-covered $\alpha-\mathrm{Al}_{2} \mathrm{O}_{3}$ sample at $\mathrm{R}_{\mathrm{SRFA}}$ $=10.9$; illustration of the parallel evolution of the intensities of the ET and $\mathrm{Bz}$ bands, $\mathrm{A}_{0, \mathrm{ET}} / \mathrm{A}_{0, \mathrm{Bz}}$, and of the width ratio $\Delta_{\mathrm{ET}} / \Delta_{\mathrm{Bz}}$, and ${ }^{7} \mathrm{~F}_{2} /{ }^{7} \mathrm{~F}_{1}$ ratios vs. [Eu]/[HS] (moleu.mol-1;site) for original HS samples. The experimental data including $\mathrm{pH}$, actual concentration of $\alpha-\mathrm{Al}_{2} \mathrm{O}_{3}$, SRFA, and PAHA, distribution coefficients are given as well as results of the fits and the fitting parameters and fitting uncertainties. Illustration of the parallel evolution of the intensities of the ET and $\mathrm{Bz}$ bands, $\mathrm{A}_{0, \mathrm{ET}} / \mathrm{A}_{0, \mathrm{Bz}}$, and of the width ratio $\Delta_{\mathrm{ET}} / \Delta_{\mathrm{Bz}}$ are also given. This information is available free of charge via the Internet at http://pubs.acs.org.

\section{References}

(1) Kretzschmar, R.; Schäfer, T. Metal retention and transport on colloidal particles in the environment. Elements 2005, 1, 205-210.

(2) Heidmann, I.; Christl, I.; Kretzschmar, R. Sorption of $\mathrm{Cu}$ and $\mathrm{Pb}$ to kaolinite-fulvic acid colloids: Assessment of sorbent interactions. Geochim. Cosmochim. Acta 2005, 69, 1675-1686.

(3) Artinger, R.; Kienzler, B.; Schußler, W.; Kim, J. I. Effects of humic substances on the ${ }^{241} \mathrm{Am}$ migration in a sandy aquifer: column experiments with Gorleben groundwater/sediment systems. J. Contam. Hydrol. 1998, 35, 261-275.

(4) Hur, J.; Schlautman, M. A. Influence of humic substance adsorptive fractionation on pyrene partitioning to dissolved and mineral-associated humic substances. Environ. Sci. Technol. 2004, 38, 5871-5877.

(5) Tipping, E.; Higgins, D. C. The effect of adsorbed humic substances on the colloid stability of haematite particles. Colloids and Surfaces 1982, 5, 85-92.

(6) Kretzschmar, R.; Hesterberg, D.; Sticher, H. Effects of adsorbed humic acid on surface charge and flocculation of kaolinite. Soil Sci. Soc. Am. J. 1997, 61, 101-108.

(7) Zachara, J. M.; Resch, C. T.; Smith, S. C. Influence of humic substances on $\mathrm{Co}^{2+}$ sorption by a subsurface mineral separate and its mineralogic components. Geochim. Cosmochim. Acta 1994, 58, 553-566.

(8) Murphy, R. J.; Lenhart, J. J.; Honeyman, B. D. The sorption of thorium (IV) and uranium (VI) to hematite in the presence of natural organic matter. Colloids Surf. A 1999, 157, 47-62.

(9) Lenhart, J. J.; Honeyman, B. D. Uranium(VI) sorption to hematite in the presence of humic acid. Geochim. Cosmochim. Acta 1999, 63, 2891-2901.

(10) Vermeer, A. W. P.; McCulloch, J. K.; van Riemsdijk, W. H.; Koopal, L. K. Metal ion adsorption to complexes of humic acid and metal oxides: Deviation from the additivity rule. Environ. Sci. Technol. 1999, 33, 38923897.

(11) Christl, I.; Kretzschmar, R. Interaction of copper and fulvic acid at the hematite-water interface. Geochim. Cosmochim. Acta 2001, 65, 3435-3442.

(12) Robertson, A. P., Goethite/humic acid interactions and their effects on copper(II) binding. Ph. D Thesis, Stanford University, Stanford, 1996. 
(13) Robertson, A. P.; Leckie, J. O. Humic acid/goethite interactions and their effet on copper binding. In Humic substances in the global environment and implication on human health; Senesi, N., Miano, T. M., Eds. Elsevier, 1994.

(14) Samadfam, M.; Sato, S.; Ohashi, H. Effects of humic acid on the sorption of $\mathrm{Eu}(\mathrm{III})$ onto kaolinite. Radiochim. Acta 1998, 82, 361365.

(15) Lumsdon, D. G. Partitioning of organic carbon, aluminium and cadmium between solid and solution in soils: application of a mineral-humic particle additivity model. Eur. J. Soil Sci. 2004, 55, 271-285.

(16) Weng, L.; Van Riemsdijk, W. H.; Hiemstra, T. Adsorption of humic acids onto goethite: Effects of molar mass, $\mathrm{pH}$ and ionic strength. J. Colloid Interface Sci. 2007, 314, 107-118.

(17) Ochs, M.; Cosovic, B.; Stumm, W. Coordinative and hydrophobic interaction of humic substances with hydrophilic $\mathrm{Al}_{2} \mathrm{O}_{3}$ and hydrophobic mercury surfaces. Geochim. Cosmochim. Acta 1994, 58, 639650.

(18) Weng, L. P.; Van Riemsdijk, W. H.; Hiemstra, T. Adsorption free energy of variable-charge nanoparticles to a charged surface in relation to the change of the average chemical state of the particles. Langmuir 2006, 22, 389-397.

(19) Davis, J. A.; Gloor, R. Adsorption of dissolved organics in lake water by aluminum oxide. Effect of molecular weight. Environ. Sci. Technol. 1981, 15, 1223-1229.

(20) Gu, B.; Schmitt, J.; Chem, Z.; Liang, L.; McCarthy, J. F. Adsorption and desorption of natural organic matter on iron oxide: Mechanisms and models. Environ. Sci. Technol. 1994, 28, 38-46.

(21) Meier, M.; Namjesnik-Dejanovic, K.; Maurice, P.; Chin, Y.-P.; Aiken, G. R. Fractionation of aquatic natural organic matter upon sorption to goethite and kaolinite. Chem. Geol. 1999, 157, 275-284.

(22) Hur, J.; Schlautman, M. A. Molecular weight fractionation of humic substances by adsorption onto minerals. J. Colloid Interface Sci. 2003, 264, 313-321.

(23) Hur, J.; Schlautman, M. A. Effects of $\mathrm{pH}$ and phosphate on the adsorptive fractionation of purified Aldrich humic acid on kaolinite and hematite. $J$. Colloid Interface Sci. 2004, 277, 264-270.

(24) Hur, J.; Schlautman, M. A. Effects of mineral surfaces on pyrene partitioning to well-characterized humic substances. $J$. Environ. Qual. 2004, 33, 1733-1742.

(25) Schlautman, M. A.; Morgan, J. J. Effects of Aqueous Chemistry on the Binding of Polycyclic Aromatic-Hydrocarbons by Dissolved Humic Materials. Environ. Sci. Technol. 1993, 27, 961-969.

(26) Gu, B.; Mehlhorn, T. L.; Liang, L.; McCarthy, J. F. Competitive adsorption, displacement, and transport of organic matter on iron oxide: I. Competitive adsorption. Geochim. Cosmochim. Acta 1996, 60, 1943-1950.

(27) Piccolo, A.; Conte, P. Molecular size of humic substances. Supramolecular associations versus macromolecular polymers (Reprinted from Advances in Environmental Research, vol 3, pg 508-521, 2000). Adv. Environ. Res. 1999, 3, -.

(28) Piccolo, A.; Conte, P.; Cozzolino, A. Chromatographic and spectrophotometric properties of dissolved humic substances compared with macromolecular polymers. Soil Sci. 2001, 166, 174-185.

(29) Kaiser, K. Sorption of natural organic matter fractions to goethite $(\alpha-\mathrm{FeOOH})$ : Effect of chemical composition as revealed by liquidstate C-13 NMR and wet-chemical analysis. Org. Geochem. 2003, 34, 1569-1579.

(30) Reiller, P.; Amekraz, B.; Moulin, C. Sorption of Aldrich humic acid onto 
hematite: Insights into fractionation phenomena by electrospray ionization with quadrupole time-of-flight mass spectrometry. Environ. Sci. Technol. 2006, 40, 2235-2241.

(31) Plancque, G.; Amekraz, B.; Moulin, V.; Toulhoat, P.; Moulin, C. Molecular structure of fulvic acids by electrospray with quadrupole time-of-flight mass spectrometry. Rapid Commun. Mass Spectrom. 2001, 15, 827-835.

(32) These, A.; Winkler, M.; Thomas, C.; Reemtsma, T. Determination of molecular formulas and structural regularities of low molecular weight fulvic acids by sizeexclusion chromatography with electrospray ionization quadrupole time-offlight mass spectrometry. Rapid Commun. Mass Spectrom. 2004, 18, 1777-1786.

(33) Moulin, V.; Reiller, P.; Amekraz, B.; Moulin, C. Direct characterization of iodine covalently bound to fulvic acids by electrospray mass spectrometry. Rapid Commun. Mass Spectrom. 2001, 15, 24882496.

(34) Rice, J. A.; Tombácz, E.; Malekani, K. Application of light and X-ray scattering to characterize the fractal properties of soil organic matter. Geoderma 1999, 88, 251264.

(35) Diallo, M. S.; Glinka, C. J.; Goddard, W. A.; Johnson, J. H. Characterization of nanoparticles and colloids in aquatic systems 1. Small angle neutron scattering investigations of Suwannee River fulvic acid aggregates in aqueous solutions. Journal of Nanoparticle Research 2005, 7, 435-448.

(36) MacCarthy, P.; Rice, J. A. Spectroscopic methods (other than NMR) for determining functionality in humic substances. In Humic substances in soil, sediment and water; Aiken, G. R., McKnight, D. M., Wershaw, R. L., MacCarthy, P., Eds. John Wiley \& Sons: New York, 1985; pp 527-559.
(37) Korshin, G. V.; Li, C.-W.; Benjamin, M. M. Monitoring the properties of natural organic matter through UV spectroscopy: A consistent theory. Water Res. 1997, 31, 1787-1795.

(38) Del Vecchio, R.; Blough, N. V. On the origin of the optical properties of humic substances. Environ. Sci. Technol. 2004, 38, 3885-3891.

(39) Korshin, G. V.; Kumke, M. U.; Li, C. W.; Frimmel, F. H. Influence of chlorination on chromophores and fluorophores in humic substances. Environ. Sci. Technol. 1999, 33, 1207-1212.

(40) Schäfer, T.; Buckau, G.; Artinger, R.; Kim, J. I.; Geyer, S.; Wolf, M.; Bleam, W. F.; Wirick, S.; Jacobsen, C. Origin and mobility of fulvic acids in the Gorleben aquifer system: implications from isotopic data and carbon/sulfur XANES. Org. Geochem. 2005, 36, 567-582.

(41) Scheinost, A. C.; Kretzschmar, R.; Christl, I.; Jacobsen, C. Carbon group chemistry of humic and fulvic acid: A comparison of $\mathrm{C}$ 1s NEXAFS and ${ }^{13} \mathrm{C}$-NMR spectroscopies. Spec. Pub. Royal Soc. Chem. 2002, 273, 3947.

(42) Claret, F.; Bauer, A.; Schäfer, T.; Griffault, L.; Lanson, B. Experimental investigation of the interaction of clays with high-pH solutions: A case study from the CallovoOxfordian formation, Meuse-Haute Marne underground laboratory (France). Clays Clay Miner. 2002, 50, 633-646.

(43) Christl, I.; Kretzschmar, R. C-1s NEXAFS spectroscopy reveals chemical fractionation of humic acid by cation-induced coagulation. Environ. Sci. Technol. 2007, 41, 1915-1920.

(44) Plancque, G.; Moulin, V.; Toulhoat, P.; Moulin, C. Europium speciation by timeresolved laser-induced fluorescence. Anal. Chim. Acta 2003, 478, 11-22.

(45) Chung, K. H.; Lee, W.; Cho, Y.; Choi, G.; Lee, C. Comparison of synchronous and 
laser-induced fluorescence spectroscopy applied to the $\mathrm{Eu}$ (III)-fulvate complexation. Talanta 2005, 65, 389-395.

(46) Claret, F.; Schäfer, T.; Rabung, T.; Wolf, M.; Bauer, A.; Buckau, G. Differences in properties and $\mathrm{Cm}(\mathrm{III})$ complexation behavior of isolated humic and fulvic acid derived from Opalinus clay and CallovoOxfordian argillite. Appl. Geochem. 2005, 20, 1158-1168.

(47) Kumke, M. U.; Eidner, S.; Kruger, T. Fluorescence quenching and luminescence sensitization in complexes of $\mathrm{Tb}^{3+}$ and $\mathrm{Eu}^{3+}$ with humic substances. Environ. Sci. Technol. 2005, 39, 9528-9533.

(48) Horrocks, W. D.; Sudnick, D. R. Lanthanide ion probes of structure in biology - Laserinduced luminescence decay constants provide a direct measure of the number of metal-coordinated water-molecules. J. Am. Chem. Soc. 1979, 101, 334-340.

(49) Plancque, G.; Maurice, Y.; Moulin, V.; Toulhoat, P.; Moulin, C. On the use of spectroscopic techniques for interaction studies, part I: Complexation between europium and small organic ligands. Appl. Spectrosc. 2005, 59, 432-441.

(50) Milne, C. J.; Kinniburgh, D. G.; Tipping, E. Generic NICA-Donnan model parameters for proton binding by humic substances. Environ. Sci. Technol. 2001, 35, 2049-2059.

(51) Kim, J. I.; Buckau, G.; Li, G. H.; Duschner, H.; Psarros, N. Characterization of humic and fulvic acids from Gorleben groundwater. Fresenius J. Anal. Chem. 1990, 338, 245-252.

(52) Alliot, C.; Bion, L.; Mercier, F.; Toulhoat, P. Effect of aqueous acetic, oxalic, and carbonic acids on the adsorption of europium(III) onto alpha-alumina. $J$. Colloid Interface Sci. 2006, 298, 573-581.

(53) van de Weerd, H.; van Riemsdijk, W. H.; Leijnse, A. Modelling the dynamic adsorption-desorption of NOM mixture: Effects of physical and chemical heterogeneity. Environ. Sci. Technol. 1999, 33, 1675-1681.

(54) Jacobsen, C.; Williams, S.; Anderson, E.; Browne, M. T.; Buckley, C. J.; Kern, D.; Kirz, J.; Rivers, M.; Zhang, X. Diffractionlimited imaging in a scanning-transmission X-ray microscope. Optics Commun. 1991, 86, 351-364.

(55) Jacobsen, C.; Wirick, S.; Flynn, G.; Zimba, C. Soft X-ray spectroscopy from image sequences with sub-100 nm spatial resolution. J. Microsc. Oxford 2000, 197, 173-184.

(56) Hitchcock, A. P.; Mancini, D. C. Bibliography and database of inner-shell excitation-spectra of gas-phase atoms and molecules. J. Electron Microsc. Rel. Phenom. 1994, 67, 1-132.

(57) Scott, A. I. Interpretation of ultraviolet spectra of natural products; Pergamon Press: New York, 1964.

(58) Bünzli, J. C. G. Luminescent probes. In Lanthanides probe in life, chemical and earth sciences - Theory and practice; Bünzli, J. C. G., Choppin, G. R., Eds. Elsevier: Amsterdam, 1989.

(59) Gu, B.; Schmitt, J.; Chem, Z.; Liang, L.; McCarthy, J. F. Adsorption and desorption of different organic matter fraction on iron oxide. Geochim. Cosmochim. Acta 1995, 59, 219-229.

(60) Vermeer, A. W. P.; van Riemsdijk, W. H.; Koopal, L. K. Adsorption of Humic Acids to Mineral Particles. 1. Specific and Electrostatic Interactions. Langmuir 1998, 14, 2810-2819.

(61) Schlautman, M. A.; Morgan, J. J. Adsorption of aquatic humic substances on colloidal-size aluminum-oxide particles Influence of solution chemistry. Geochim. Cosmochim. Acta 1994, 58, 4293-4303.

(62) Schäfer, T.; Claret, F.; Bauer, A.; Griffault, L.; Ferrage, E.; Lanson, B. Natural organic matter (NOM)-clay association and impact 
on Callovo-Oxfordian clay stability in high alkaline Solution: Spectromicroscopic evidence. J. Phys. IV 2003, 104, 413-416.

(63) Dhez, O.; Ade, H.; Urquhart, S. G. Calibrated NEXAFS spectra of some common polymers. J. Electron Microsc. Rel. Phenom. 2003, 128, 85-96.

(64) Cody, G. D.; Botto, R. E.; Ade, H.; Behal, S.; Disko, M.; Wirick, S. Inner-shell spectroscopy and imaging of a subbituminous coal - In-situ analysis of organic and inorganic microstructure using C(1S)-NEXAFS, Ca(2P)-NEXAFS, and C1(2S)-NEXAFS. Energy Fuels 1995, 9, 525-533.

(65) Urquhart, S. G.; Ade, H. Trends in the carbonyl core (C 1s, O 1s) $\rightarrow \pi^{*}{ }_{\mathrm{c}=\mathrm{o}}$ transition in the near-edge $\mathrm{X}$-ray absorption fine structure spectra of organic molecules. J. Phys. Chem. B 2002, 106, 8531-8538.

(66) Hitchcock, A. P.; Brion, C. E. Inner-shell excitation of formaldehyde, acetaldehyde and acetone studied by electron-impact. $J$. Electron Microsc. Rel. Phenom. 1980, 19, 231-250.

(67) Ade, H.; Zhang, X.; Cameron, S.; Costello, C.; Kirz, J.; Williams, S. Chemical contrast in X-ray microscopy and spatially resolved
XANES spectroscopy of organic specimens. Science 1992, 258, 972-975.

(68) Lindsay, R.; Gutierrez-Sosa, A.; Thornton, G.; Ludviksson, A.; Parker, S.; Campbell, C. T. NEXAFS study of $\mathrm{CO}$ adsorption on $\mathrm{ZnO}(000(1)$ over-bar1)-O and $\mathrm{ZnO}$ (000(1)over-bar)-O/Cu. Surf. Sci. 1999, 439, 131-138.

(69) Conte, P.; Piccolo, A. Conformational arrangement of dissolved humic substances. Influence of solution composition on association of humic molecules. Environ. Sci. Technol. 1999, 33, 1682-1690.

(70) Kim, J. I.; Rhee, D. S.; Buckau, G. Complexation of Am(III) with humic acids of different origin. Radiochim. Acta 1991, 52/53, 49-55.

(71) Buckau, G.; Kim, J. I.; Klenze, R.; Rhee, D. S.; Wimmer, H. A comparative spectroscopic study of the fulvate complexation of trivalent transuranium ions. Radiochim. Acta 1992, 57, 105-111.

(72) Alpha, B.; Ballardini, R.; Balzani, V.; Lehn, J.-M.; Perathoner, S.; Sabbatini, N. Antenna effect in luminescent lanthanide cryptates A photophysical study. Photochem. Photobiol. 1990, 52, 299-306. 